\title{
INTRODUCTION \\ What can demographers contribute to the study of vulnerability?
}

\author{
Raya Muttarak, Wolfgang Lutz and Leiwen Jiang*
}

\section{Introduction}

The empirical analysis of the vulnerability of people to recent natural disasters is probably the best way to get an analytical handle on estimating the levels of human vulnerability that could result from the intensifying consequences of climate change in the future. This empirical approach is based on the underlying assumption that the vulnerability to past climate-related disasters, such as flooding, storms, and droughts, is isomorphic to the likely future vulnerability to climate change. While the risks and the exposure levels of human populations to extreme weather events may change across regions as climate systems shift, it is also evident that not all people who are living in the same region that is affected by a natural disaster are equally vulnerable to disaster-related mortality or injury. As is the case for other mortality risks, people tend to be differentially vulnerable according to their age, gender, level of education, occupation, and other social and economic variables. This demographic differential vulnerability has, however, not yet been thoroughly studied. This is where we believe that demographers can make an important contribution to the study of the consequences of climate change and this is the rationale for this special issue of the Vienna Yearbook of Population Research.

\footnotetext{
* Raya Muttarak (corresponding author), Wittgenstein Centre for Demography and Global Human Capital (IIASA, VID/ÖAW, WU), International Institute for Applied Systems Analysis (IIASA), Vienna Institute of Demography, Austrian Academy of Sciences, Vienna, Austria

Email: muttarak@iiasa.ac.at

Wolfgang Lutz, Wittgenstein Centre for Demography and Global Human Capital (IIASA, VID/ÖAW, WU), International Institute for Applied Systems Analysis (IIASA), Vienna Institute of Demography, Austrian Academy of Sciences, Vienna University of Economics and Business (WU), Vienna, Austria Leiwen Jiang, Asian Demographic Research Institute (ADRI), Shanghai University, Shanghai, China and National Center for Atmospheric Research, Boulder, Colorado, USA
} 
Our decision to make demographically differentiated vulnerability to climaterelated disasters the focus of this special issue is highly timely. Climate action is one of the priorities of the new Sustainable Development Goals (SDGs) endorsed by world leaders at the United Nations (UN) Summit for Sustainable Development in September 2015. The SDG's Goal 13 is to fight climate change by both reducing emissions and promoting adaptive responses to reduce the adverse impacts of the changing climate. As for the latter target, understanding who is vulnerable and to what is a fundamental question in vulnerability reduction efforts. Here we argue that the concept of vulnerability should only be applied to living creatures, and that the well-being of humans should be at the center of our concern about the effects of climate change. We also point out that vulnerability is differentiated across different sub-groups of a population, and argue that an explicit focus on demographic differential vulnerability should therefore be incorporated into vulnerability reduction policies.

The term vulnerability has been widely used in the context of climate change, but different scholars tend to use it in different ways, often without providing a clear definition. For instance, vulnerability can be defined in terms of exposure (biophysical conditions making people or places vulnerable to hazards), social conditions (measure of resilience to hazards), outcomes (the projected impacts of climate change on a particular exposure unit), or contextual conditions (e.g. economic, political, institutional, and technological structures and processes that influence vulnerability) (O'Brien et al. 2007; Cutter 1996). Generally, the variation in the use of the term vulnerability stems from different research needs, research methods, and normative implications in different disciplines.

In its recent Fifth Assessment Report, the Intergovernmental Panel on Climate Change (IPCC) defined vulnerability as "the propensity or predisposition to be adversely affected. Vulnerability encompasses a variety of concepts and elements including sensitivity or susceptibility to harm and lack of capacity to cope and adapt." (IPCC 2014). In this context, vulnerability is clearly delineated as a characteristic of a living unit that influences its susceptibility to being harmed by external shocks, as well as its capacity to anticipate, respond to, cope with, and recover from the impact of such shocks. The term vulnerability has, however, also been used to refer to a physical dimension of a system or a place such as the potential climatic threats on the regions that are affected (IPCC 1996). In accordance with the IPCC definition, we further contend that it is misleading to focus on vulnerability of the systems per se, and that the adverse effects on people who are embedded in the systems should be of primary concern. Natural or social systems can, of course, collapse, but whether such an event is seen as threatening or welcome-e.g. the collapse of a dictatorial regime-depends on its effects on human well-being. The concept of social vulnerability therefore emphasizes the inherent properties of human systems that make individuals or groups susceptible to damage from external hazards, as well as people's abilities to respond to and recover from the impacts of disasters (Blaikie et al. 1994; Adger 1999). While the term social vulnerability is commonly used to distinguish the vulnerability of human systems from the 
vulnerability of non-human (nature) systems, it still does not explicitly state that human beings are the vulnerable unit.

Furthermore, given that the impacts of climate change are not evenly distributed within a regionally defined population, we need a more vigorous incorporation of the concept of demographic differential vulnerability into vulnerability analyses and policy measures aimed at reducing vulnerability. Indeed, this approach has already been highlighted as a key to sustainable development by international experts, first in preparation for the United Nations (UN) World Summit on Sustainable Development in 2002 (Lutz and Shah 2002), and a decade later in preparation for the RIO+20 Earth Summit (Lutz et al. 2012). These experts emphasized that vulnerability to environmental changes and the capacity to adapt to these changes vary not only between countries, regions, communities, and households; but also between family members depending on age and gender. Failing to recognize demographic heterogeneity in vulnerability can lead to the formulation of policies that are not appropriately directed at the truly vulnerable groups.

\section{Contributions of demography to the understanding of differential vulnerability}

Demography has an analytical and methodological tool box and profound knowledge about population dynamics that can be used in several ways to measure demographic differential vulnerability in the context of climate change. First, the topic of differentials across population subgroups has long been a focus in demographic research. Second, the notion of 'hazard function', which was originally derived from the risk of dying by age and sex, is central to demographic methodology, and thus lends itself to the study of differential vulnerability. Third, demography is a discipline built upon empirical evidence and facts that are quantifiable. For example, having knowledge of a population's distribution and composition makes it possible to estimate which members of this population are most at risk to certain natural hazards both in terms of where they are and who they are. Fourth, demography also provides tools for forecasting. For instance, using multi-dimensional population projection methods it is possible to project into the future the age-sex-education composition of societies, and thus to quantitatively forecast the vulnerable segments of the population within countries and regions. Moreover, it is possible to produce population projections in a probabilistic way-a method that could prove particularly useful for policy planning when uncertainty in population forecasting needs to be accounted for (Lutz et al. 1997; Raftery et al. 2012).

While conventional demographic methods only considered age and sex as demographic factors, education, a characteristic that is highly relevant to reducing vulnerability, has recently been introduced as another demographic component in population projections (Lutz et al. 2014). Research has shown that the 
changing educational composition of populations stratified by age and sex is a key determinant of future socioeconomic challenges, ranging from total population size (Lutz and KC 2011), to economic growth (Lutz et al. 2008), to disaster mortality (Lutz et al. 2014). Depending on the context, other demographic characteristics, such as labor force participation, marital status, ethnicity, and religion, have also been included in such demographic models.

Indeed, demography is highly relevant to the study of global environmental change since human beings are at the center of the environmental system, both as the driver of and as the unit being affected by climate change. On the one hand, human activities, particularly the burning of fossil fuels, are responsible for the increased concentration of greenhouse gases in Earth's atmosphere, which has contributed to the increasing average global temperatures and consequently caused climate change. On the other hand, the recently observed increases in the intensity and the frequency of extreme weather events, coupled with water scarcity and climaterelated food insecurity, appear to be having serious effects on the livelihoods and the well-being of people. The impacts of climate change have already been felt, especially in developing countries with high population growth, poor infrastructure, and a lack of urban planning. It is certainly the case that taking steps to adapt to anticipated climate change-e.g. adjusting planting dates and crop variety, retrofitting buildings, and engaging in disaster risk management—will be necessary to reduce the adverse impacts of climate change. Similarly, mitigation actions, such as technology development and behavioural changes, can help to reduce emissions. However, there is a large degree of heterogeneity within populations, as captured by observable characteristics such as age, gender, education, income, and place of residence; and these demographic differentials may be expected to determine the capacity to mitigate and adapt (Lutz and Striessnig 2015; O'Neill et al. 2010). For instance, it has been shown that countries, communities, households, and individuals with higher levels of education are less vulnerable to natural disasters than their less educated counterparts (Muttarak and Lutz 2014). Different socioeconomic development paths and policies can thus be expected to influence population dynamics and societies' capacities to achieve sustainability and to adapt likewise.

Given the close link between human population and the climate system, demography, as a scientific discipline with powerful methodological tools, can contribute significantly to the estimation and forecasting of population dynamics and population heterogeneity in climate change models. For example, having knowledge of which population subgroups are more likely to be vulnerable to specific types of natural hazards (as shown in this special issue) can assist policy-makers in crafting appropriate interventions aimed at reducing vulnerability. Surprisingly, climate change and differential vulnerability remains a marginal topic of study among demographers (Muttarak et al. 2016). This also results in the underrepresentation of demographers among major scientific efforts related to vulnerability and climate change, including in the IPCC reports. 


\section{About this special issue 'Demographic differential vulnerability to climate-related disasters'}

This special issue is a product of the growing recognition of the need for scholars of population studies and of other social science disciplines to pay greater attention to the issue of demographic differential vulnerability. The special issue is a result of the international scientific conference of the IUSSP (International Union for the Scientific Study of Population) Panel on Climate Change, 'Demographic Differential Vulnerability to Natural Disasters in the Context of Climate Change Adaptation', held in Kao Lak, Phang Nga province, Thailand on 23-25 April 2014. The conference was jointly organized by the College of Population Studies, Chulalongkorn University, Bangkok; the Wittgenstein Centre for Demography and Human Capital (IIASA, VID/ÖAW and WU); and the IUSSP Panel on Climate Change. The conference was funded by the Chula Global Network and the European Research Council ('Forecasting Societies Adaptive Capacities to Climate Change', PI: Wolfgang Lutz, grant agreement: ERC-2008-AdG 230195-FutureSoc).

\subsection{Demographic debate}

The issue opens with a Demographic Debate section, which is comprised of five contributions from distinguished demographers across different continents. As we mentioned above, the study of environmental change has yet to become popular among demographers. In this section, distinguished demographers from different continents therefore address the following question: Why are so few demographers working on population and climate change? The reasons cited in these articles are summarized below:

1. The complexity of climate science and the limitations of data and methods for integrating the environmental and climate context into the microdata commonly used by demographers. With a focus on empirical science, it takes longer time for demographers to address new research questions such as climate change if appropriate data are not available (Hayes; Hunter and Menken).

2. The lack of interdisciplinary collaboration, despite the interconnectedness of the issues of population and climate change. This results in inadequacy of the climate models (e.g. the integrated assessment models (IAM) of the IPCC) in accounting for the social and demographic components (Gage; Hayes; Hunter and Menken; Peng and Zhu).

3. The discomfort with addressing population and environment issues given the historical involvement of demographers in the controversial debates during the late 1960s and 1970s on the limits to population growth, which were triggered by concerns about the limits to natural resources. As these debates raised complex and sensitive policy questions, demographers have become reluctant 
to engage with climate change and environmental issues (Gage; Mcdonald; Peng and Zhu).

4. The research topics surrounding climate change, such as production and consumption and disaster vulnerability, are more directly related to other social science disciplines (e.g. economics, political science, geography) than demography. As anthropogenic climate change is a 'social problem' inherently related to human values, demographers are required to go beyond a mere emphasis on empirical relationships between population and climate systems when investigating this issue (Hayes; Peng and Zhu).

5. Limitations in funding, especially because funders of climate change research tend to value natural science approaches more than social science approaches (Peng and Zhu).

Although demographers have shown relatively little interest in climate change research until now, one common message across the five contributions to the Demographic Debate section is the promising potentials for population researchers to engage in climate change research following recent developments in data and methodological tools. In addition, as Hunter and Menken pointed out, conventional research topics in demography, such as fertility, mortality, and migration, are linked to global environmental change. The recognition of these common interests should spur the involvement of population scholars in the field of climate change research. Moreover, a few population scholars have already engaged in climate change research, and have introduced the population dimension into climate change modelling. Activities of the IUSSP Climate Change Panel, coupled with recent initiatives - such as an initiative in China that established new degree programs explicitly focusing on population and environment-should encourage younger generations of demographers to participate in the field of climate change research.

The Demographic Debate section concludes with an essay by Wolfgang Lutz that highlights the contributions demographers can make to research on sustainable development, especially by providing estimates and forecasts of population dynamics, which are fundamental to policy design. This essay is accompanied by a reprint of the two statements made by distinguished international scientists on the importance of placing human populations, and the composition and the distribution of these populations, at the center of sustainable development research (Lutz and Shah 2002; Lutz et al. 2012). Indeed, climate change and sustainable development are closely related, as both of these socioeconomic development paths result not only in different levels of greenhouse gas emissions, but in differential adaptive capacities depending on the composition and the distribution of populations (Lutz and Striessnig 2015; KC and Lutz 2014a). It is therefore clear that demography is a scientific discipline that can make important contributions to our understanding of the complex relationship between human populations and the climate system, and of what society will look like in the future based on population projections. 


\subsection{Research articles}

The nine original and fully refereed research articles presented in this special issue highlight how scholars of population studies and other relevant disciplines can contribute to our understanding of population and climate change interactions. These articles address the issue of demographic differential vulnerability from different perspectives on vulnerability, drawing upon case studies from across the globe based on unique data and innovative methodologies. This collection of research articles offers both empirical studies and forecasts of future vulnerability based on national- and global-level evidence.

Vulnerability in this context refers to 'outcome vulnerability'; that is, the negative outcome of climate change on a particular unit, or human being, that can be quantified and measured (O'Brien et al. 2007). After establishing that the human being is the unit that is vulnerable, the next question is what hazards people are vulnerable to. Premature death is obviously the most undesirable outcome, as it harms the deceased and deprives him or her of all of the benefits of being alive (Feldman 1991). Also, after death the individual has no chance for recovery and no capacity to adapt. Falling ill, losing a job, or losing a crop are also unwelcome events, but they do not kill the individual; there still is a chance for recovery and adaptation. Likewise, the consequences of certain unwelcome episodes, such as catching the flu, may not be entirely negative, as contracting an illness could boost the person's immune system. Death, on the other hand, is universally seen as an unfavorable outcome, and can be measured unambiguously: a person is either dead or alive, and all countries have clear legal definitions of death. This focus on premature human mortality also makes the measurement and the assessment of vulnerability much easier, as death is a globally valid metric. There are several ways to operationalize the notion of premature mortality, such as through estimating agesex specific years of life lost due to premature mortality and disability, as was done in the Global Burden of Disease study (Murray and Lopez 2013).

In this special issue, Zagheni et al. and Zhao et al. explicitly investigated mortality risks from climate extremes, such as hydrological hazards (flood and storm) and extreme temperatures, which are likely to be further aggravated by climate change. Focusing on mortality from extreme temperatures in Taiwan in the 1970s, Zhao et al. showed that both unusually cold temperatures in winter and unusually hot temperatures in summer were associated with higher mortality. However, the mortality patterns differed by age group and cause of death, with older people being more likely to die from cardiovascular disease during extreme cold episodes, and children and young adults being more likely to die from drowning during hot spells. These mortality patterns have, however, changed in recent decades due to socioeconomic developments in Taiwan, which brought about improvements in health care, living environments, safety management, and disease prevention practices. Similarly, the analysis of cause-of-death data for 63 countries in the years 1995-2011 by Zagheni et al. found that mortality from hydrometeorological disasters declined over this period as a result of improvements 
in human development. Contradicting the common belief that women are more vulnerable to natural disasters than men, Zagheni et al. found that in the case of mortality risks from floods and storms, men, and especially young adult men, had much higher mortality levels than women. The findings on age-sex differentials in mortality risks from different types of natural disasters thus have important implications for designing appropriate policy responses to address the differential vulnerability of different demographic subgroups.

Apart from understanding who is vulnerable to what, equally importantly where people live determine their exposure to natural hazards. For instance, even older people and young children, who are generally more likely to die from tsunamis than people in other age groups, are not more vulnerable if they live in an area that is not exposed to tsunami hazards. The articles by de Sherbinin and Bardy and by Ignacio et al. contribute spatial perspectives to the analysis of differential vulnerability. In particular, the two articles address the important question of whether the subgroups of the population who are socioeconomically disadvantaged - e.g. people who have low incomes, low levels of education, or high unemployment rates; or are members of ethnic minority groups-are also more likely to live in areas with higher levels of exposure to natural hazards. In geography, this question is often approached by developing an index of social vulnerability, or a composite measure of various demographic and socioeconomic characteristics of a geographical unit, to identify a vulnerable area. The articles by de Sherbinin and Bardy and by Ignacio et al. contribute to the empirical advancement in the field by further investigating how well the social vulnerability indices correspond with actual losses and damages after a disaster strikes. This exercise allowed for the validation of the social vulnerability indices, which is rarely done in vulnerability assessment studies (Fekete 2009).

De Sherbinin and Bardy employed census data to develop social vulnerability indices of two major cities, New York City and Mumbai, which are considered to be among the top 10 port cities most exposed to coastal flooding. Exploiting the events of Hurricane Sandy in 2012 for New York City and of the Maharashtra floods in 2005 for Mumbai, the article investigated whether the areas with higher social vulnerability scores were also more likely to be inundated. This was found to be the case for Mumbai, but not for New York City. While these findings may be attributable in part to data limitations and the different spatial resolutions used, the two cities may also differ in terms of settlement preferences, with, for instance, wealthy households in New York preferring to live along the coastline. Indeed, the findings from the case study of the Tropical Storm Washi flood in the southern Philippines in 2011 by Ignacio et al. suggest that the areas along the riverbanks most prone to severe flooding were predominantly inhabited by the middle class. In addition to adopting only a composite score of the social vulnerability indices commonly used in other studies, Ignacio et al. decomposed the indices in order to determine which demographic and socioeconomic factors contributed to disaster vulnerability. They found that physical characteristics that determine exposure to flooding, such as elevation from the coast and slope, explained the losses and the 
damages better than the socio-demographic characteristics of the areas. Given the extreme nature of the flood event they investigated, exposure was an important determinant of vulnerability. Nevertheless, Ignacio et al. pointed out that it is still important for policy-makers responsible for crafting disaster risk reduction measures to consider the differential capacity of the population to get out of harm's way.

Risk perceptions, attitudes toward climate change, and climate-related behaviors also vary considerably by demographic and socioeconomic characteristics. Understanding public attitudes and perceptions is essential not only for formulating education and communication strategies, but for successfully implementing risk reduction or adaptation strategies. For instance, identifying the factors that influence household hurricane evacuation decisions can contribute to the development of effective protective actions for hurricanes (Huang et al. 2015). The article by Meijer-Irons offers a unique analysis of panel surveys from rural Thailand that compared subjective assessments of environmental risks with objective measures of environmental and climate conditions, such as the vegetation health index. In particular, Meijer-Irons showed that subjective perceptions of environmental risks depend on household characteristics and economic activities. Households that, relative to the average, were large, had a high level of involvement in agriculture, and had a large number of members who were working-age women or older people, were more likely to report that their income losses were due to environmental shocks, after controlling for objectively measured climate conditions of the areas. This finding implies that policies aiming to address the impacts of environmental change should take into account the issues that are most crucial to different subgroups of people who are vulnerable to environmental shocks. The paper by Muttarak and Chankrajang investigated the relationships between climate change perceptions and climate-relevant behaviors, i.e. the actions individuals take to minimize the problem of global warming (mitigation actions) in Thailand. Their results showed that while concerns about global warming were associated with climate-relevant behaviors, this association applied to actions that involved making technical and behavioral changes (e.g. using energy-efficient electrical devices, using a cloth bag instead of a plastic bag, and planting trees), but not to those actions that involved saving electricity and water (e.g. turning off unused lights and turning off the tap while brushing teeth). Similarly, educational differences were found for the former set of behaviors, but not for the latter. The findings further showed that achieving technical and behavioral changes generally involved making consistent efforts to change behavior, knowing what actions to take, and having a certain level of concern about anthropogenic impacts on climate change; whereas saving electricity and water was often undertaken simply for economic reasons. Educational differentials in climate actions thus depend on the motivations for carrying out the action.

Finally, the final three papers in the special issue offer a forecast of the future vulnerability and adaptive capacities of societies through the lens of human capital based on a multi-dimensional population projection exercise and the application 
of the newly developed Shared Socioeconomic Pathways (SSPs). Population and human capital projections were carried out following the five scenarios as defined by the SSPs (KC and Lutz 2014b). The SSP narratives described alternative socioeconomic development pathways that influence population dynamics and human capital formation for different world regions. Building upon recent solid evidence on the role of human capital (measured as education) in reducing vulnerability to natural disasters (Muttarak and Lutz 2014; Lutz et al. 2014) - from mortality, morbidity, disaster responses, coping strategies to recovery -, the three articles showed that differences in population size and composition in the different SSPs are expected to result in varying degrees of vulnerability in the future.

Based on the estimation of disaster mortality for the years 1970-2010 covering 174 countries, Striessnig and Loichinger confirmed that countries with a higher proportion of women with at least secondary education experienced far fewer deaths due to climate-related extreme natural events. The results were then translated into the predicted number of deaths, and the future fatalities are projected according to changes in the educational composition of population derived from the five SSPs scenarios in each major world region. Striessnig and Lochinger found that future disaster deaths vary considerably in the SSP scenarios, especially for Latin America and the Caribbean, Asia, and Africa, where the room for educational expansion is greater than it is in other regions. Similarly, Crespo Cuaresma and Lutz further extended our understanding of future societies' adaptive capacity by projecting how the Human Development Index (HDI) varies under different SSP scenarios. The HDI is composed of three components: income, educational attainment, and life expectancy (as a proxy for health). Previous studies have shown that each of these components is a key determinant of vulnerability to natural disasters (Striessnig et al. 2013; Patt et al. 2010). Indeed, the paper by Zagheni et al. in this issue demonstrated that disaster-related mortality steadily declines as a country's HDI level increases. Exploiting the new life expectancy and educational attainment projections by the Wittgenstein Centre for Demography and Global Human Capital (Lutz et al. 2014), coupled with the projections of income per capita growth by Crespo Cuaresma (2015) under the five SSP scenarios, Crespo Cuaresma and Lutz were for the first time able to produce HDI projections for 154 countries up to the end of this century. As in the article by Striessnig and Loichinger, the HDI projection exercise found that the degree of vulnerability to climate change varies based on different development trajectories.

Finally, the article by Loichinger, KC, and Lutz presents an innovative application of multi-dimensional population projections to forecast future adaptive capacities at the sub-national level, using the Phang Nga province located in the south of Thailand as a case study. The size and the composition of the population of Phang Nga, the Thai province most severely affected by the Indian Ocean tsunami in 2004 , is projected by age, sex, level of education, and labor force participation. This four-dimensional module made it possible to forecast the level of adaptive capacity of the Phang Nga province using the relatively comprehensive understanding of population dynamics and future changes in distribution and composition of the 
population of Phang Nga. As has been shown that individuals with higher levels of education were better prepared for disasters (Muttarak and Pothisiri 2013; Hoffmann and Muttarak 2015), given the shift in the educational composition of the province's labor force toward higher levels, it may be assumed that the population will have higher levels of disaster preparedness in the future.

These nine original research articles not only enrich our understanding of different dimensions of demographic differential vulnerability in various geographical contexts; they also demonstrate how demographic methodological tools and data can be applied to the study of vulnerability. In particular, the application of demographic knowledge in investigating and forecasting demographic differential vulnerability is a key contribution of demographers to the vulnerability research community. Although the research in this field is still in its infancy in the context of mainstream population studies, as was highlighted in the Demographic Debate section, there is considerable potential for the further development of climate change research in demography. It is clear that advancements in research on population and environment with a focus on demographic differentials must be made by younger generation of demographers, who-relative to their older colleagues - are less influenced by historical polemics on population control, and are more prepared to incorporate new challenges like climate change issue into their research.

\section{References}

Adger, N. W. 1999. Social vulnerability to climate change and extremes in coastal Vietnam. World Development 27(2): 249-69.

Blaikie, P. M., T. Cannon, I. Davis and B. Wisner 1994. At risk: Natural hazards, people's vulnerability, and disasters. London: Routledge.

Crespo Cuaresma, J. 2015. Income projections for climate change research: A framework based on human capital dynamics. Global Environmental Change, in press. doi:10.1016/j.gloenvcha.2015.02.012.

Cutter, S. L. 1996. Vulnerability to environmental hazards. Progress in Human Geography 20(4): 529-39.

Fekete, A. 2009. Validation of a social vulnerability index in context to river-floods in Germany. Natural Hazards and Earth System Science 9(2): 393-403.

Feldman, F. 1991. Some puzzles about the evil of death. Philosophical Review 100(2): 205-27.

Hoffmann, R. and R. Muttarak 2015. A tale of disaster experience in two countries: Does education promote disaster preparedness in the Philippines and Thailand. VID Working Paper 9/215. Vienna, Austria: Vienna Institute of Demography of the Austrian Academy of Sciences. http://www.oeaw.ac.at/vid/download/WP2015_09.pdf.

Huang, S.-K., M. K. Lindell and C. S. Prater 2015. Who leaves and who stays? A review and statistical meta-analysis of hurricane evacuation studies. Environment and Behavior, online version. doi:10.1177/0013916515578485. 
IPCC 1996. Climate change 1995: Impacts, adaptations and mitigation of climate change: Summary for policymakers. Geneva: Intergovernmental panel on climate change and world meteorological organisation.

IPCC 2014. Summary for policymakers. In Climate change 2014: Impacts, adaptation, and vulnerability. Part A: Global and sectoral aspects. Contribution of working group II to the fifth assessment report of the intergovernmental panel on climate change, eds $\mathrm{C}$. B. Field, V. R. Barros, D. J. Dokken, K. J. Mach, M. D. Mastrandrea, T. E. Bilir, M. Chatterjee, et al., 1-32. Cambridge, UK, and New York, NY, USA: Cambridge University Press.

KC, S. and W. Lutz 2014a. Alternative scenarios in the context of sustainable development. In World Population and Human Capital in the 21st Century, eds W. Lutz, W. P. Butz and S. KC, 591-627. Oxford, UK: Oxford University Press.

KC, S. and W. Lutz 2014b. Demographic scenarios by age, sex and education corresponding to the SSP narratives. Population and Environment 35(3): 243-60.

Lutz, W., W. P. Butz, M. Castro, P. Dasgupta, P. G. Demeny, I. Ehrlich, S. Giorguli, et al. 2012. Demography's role in sustainable development. Science 335(6071): 918-918.

Lutz, W., W. P. Butz and S. KC (eds) 2014. World Population and Human Capital in the 21st Century. Oxford, UK: Oxford University Press.

Lutz, W., J. Crespo Cuaresma and W. C. Sanderson 2008. The demography of educational attainment and economic growth. Science 319(5866): 1047-48.

Lutz, W. and S. KC 2011. Global human capital: Integrating education and population. Science 333(6042): 587-92.

Lutz, W., R. Muttarak and E. Striessnig 2014. Universal education is key to enhanced climate adaptation. Science 346(6213): 1061-62.

Lutz, W., W. C. Sanderson and S. Scherbov 1997. Doubling of world population unlikely. Nature 387(6635): 803-5.

Lutz, W. and M. Shah 2002. Population should be on the Johannesburg agenda. Nature 418(6893): 17-17.

Lutz, W. and E. Striessnig 2015. Demographic aspects of climate change mitigation and adaptation. Population Studies 69(supp1): S69-76.

Murray, C. J. L. and A. D. Lopez 2013. Measuring the global burden of disease. New England Journal of Medicine 369(5): 448-57.

Muttarak, R., G. J. Abel, V. Bordone and E. Zagheni 2016. Bowling together: Scientific collaboration networks of European demographers. Presented at the European Population Conference 2016, Mainz, Germany.

Muttarak, R. and W. Lutz 2014. Is education a key to reducing vulnerability to natural disasters and hence unavoidable climate change? Ecology $\mathcal{F}$ Society 19(1): 1-8.

Muttarak, R. and W. Pothisiri 2013. The role of education on disaster preparedness: Case Study of 2012 Indian Ocean Earthquakes on Thailand's Andaman Coast. Ecology $\mathcal{F}$ Society 18(4): 51.

O’Brien, K., S. Eriksen, L. Nygaard and A. Schjolden 2007. Why different interpretations of vulnerability matter in climate change discourses. Climate Policy 7(1): 73-88. 
O’Neill, B. C., M. Dalton, R. Fuchs, L. Jiang, S. Pachauri and K. Zigova 2010. Global demographic trends and future carbon emissions. Proceedings of the National Academy of Sciences 107(41): 17521-26.

Patt, A. G., M. Tadross, P. Nussbaumer, K. Asante, M. Metzger, J. Rafael, A. Goujon and G. Brundrit 2010. Estimating least-developed countries' vulnerability to climate-related extreme events over the next 50 years. Proceedings of the National Academy of Sciences 107(4): 1333-37.

Raftery, A. E., N. Li, H. Ševčíková, P. Gerland and G. K. Heilig 2012. Bayesian probabilistic population projections for all countries. Proceedings of the National Academy of Sciences 109(35): 13915-21.

Striessnig, E., W. Lutz and A. G. Patt 2013. Effects of educational attainment on climate risk vulnerability. Ecology $\mathcal{E}$ Society 18(1): 16. 